\title{
CM Tools and Pearls: The Canadian Diabetes Association 2013 Clinical Practice Guidelines
}

Julie Gilmour MBChB FRCPC, Catherine Yu MD FRCPC MHSc

$\begin{aligned} & \text { About the Authors } \\ & \text { Julie Gilmour is a resident and Catherine Yu is a member of staff, both at the Division } \\ & \text { of Endocrinology and Metabolism at the University of Toronto, in Toronto, Ontario. } \\ & \text { Correspondence may be directed to yuca@smh.ca.the Department of Oncology at } \\ & \text { McGill University in Montreal, QC, Canada. Correspondence may be directed to } \\ & \text { yuca@smh.ca. }\end{aligned}$
Gulmour

\section{Summary}

Diabetes is common in Canada, and over the last decade, the incidence of diabetes has grown rapidly. The Canadian Diabetes Association (CDA) released the 2013 Clinical Practice Guidelines for the Prevention and Management of Diabetes in Canada (CPGs) in April 2013. These internationally recognized guidelines provide recommendations on screening, prevention, diagnosis, education, and management of diabetes. This article summarizes four key messages in diabetes care, including diagnosis, glucose lowering, vascular protection, and organization of care. Information on how to access the CDA's interactive online and mobile applications is also provided.

\section{Résumé}

Le diabète est courant au Canada et, dans la dernière décennie, son incidence a grimpé en flèche. En avril 2013, l'Association canadienne du diabète a publié un guide de pratique clinique sur le sujet : 2013 Clinical Practice Guidelines for the Prevention and Management of Diabetes in Canada. Jouissant d'une notoriété internationale, ces lignes directrices renferment des recommandations sur le dépistage, la prévention, le diagnostic et le traitement du diabète ainsi que sur l'éducation dans ce domaine. Le présent article résume quatre messages principaux sur la prise en charge de la maladie, plus précisément sur le diagnostic, la baisse de la glycémie, la protection vasculaire et l'organisation des soins. Il offre également des conseils sur les applications en ligne et les applications mobiles de l'Association canadienne du diabète. 


\section{Introduction}

Diabetes is common in Canada, and over the last decade, the incidence of diabetes has grown rapidly. Between 1998 and 2009 , there was a $230 \%$ increase in the number of individuals with diabetes, and it is estimated that by $2019,3.7$ million people in Canada will be living with diabetes. ${ }^{1}$

The Canadian Diabetes Association (CDA) released the 2013 Clinical Practice Guidelines for the Prevention and Management of Diabetes in Canada (CPGs) in April 2013. ${ }^{2}$ These internationally recognized guidelines provide recommendations on screening, prevention, diagnosis, education, care, and management of diabetes.

In this article, we highlight four key messages and refer to useful tools from these guidelines: diagnosis, glucose lowering, vascular protection, and organization of care.

\section{What's New in the Diagnosis of Diabetes?}

Glycosylated hemoglobin (hemoglobin A1C) has now been incorporated into the diagnostic criteria for diabetes, in addition to the traditional criteria, outlined in Table 1. A1C should not be used for diagnosis in individuals suspected of having type 1 diabetes, or in situations that can falsely alter its value, such as hemoglobinopathies.

\section{How Will I Remember this?}

The CDA has created a suite of online tools, including one for screening and diagnosis. This can be accessed through the CDA website, as well as on the mobile application. ${ }^{3}$

\section{What A1C Should I Target?}

The CDA CPG recommends that glycemic control targets should be individualized (Figure 1). Many individuals will have an A1C target of $\leq 7 \%$. This target is based on randomized control trial (RCT) data from the landmark United Kingdom Prospective Diabetes Study (UKPDS) and Diabetes Control and Complications Trial (DCCT), both of which showed the beneficial effects of improved glycemic control on the prevention of microvascular complications. ${ }^{4,5}$ Furthermore, the 10-year follow-up study from the UKPDS demonstrated a legacy effect of earlier glucose control, with a $15-33 \%$ reduction in myocardial infarction (MI) and a $13-27 \%$ reduction in allcause mortality. ${ }^{6}$ In the Epidemiology of Diabetes Interventions and Complications (EDIC) follow-up study of the DCCT, there was a $42 \%$ reduction in cardiovascular (CV) outcomes. ${ }^{7}$

New in these guidelines, a less stringent A1C target (7.1$8.5 \%$ ) has been suggested for individuals with limited life expectancies, high levels of functional dependency, extensive coronary artery disease at high risk of ischemic events, multiple comorbidities, a history of recurrent severe hypoglycemia, and longstanding diabetes for whom it is difficult to achieve an A1C $\leq 7 \%$, despite effective doses of multiple anti-hyperglycemic agents (including intensified basal and bolus insulin).

In contrast, a more aggressive $\mathrm{A} 1 \mathrm{C}$ target can be considered in some patients with type 2 diabetes, to further reduce their risk of nephropathy and retinopathy. In the Action in Diabetes and Vascular Disease: Preterax and Diamicron MR Controlled Evaluation (ADVANCE trial), there was a $21 \%$ relative reduction in nephropathy in those undergoing intensive

\begin{tabular}{|c|c|c|}
\hline Test & Result & $\begin{array}{l}\text { Dysglycemia } \\
\text { category }\end{array}$ \\
\hline \multirow{2}{*}{$\begin{array}{l}\text { FPG (mmol/L) } \\
\text { - No caloric intake for at least } 8 \text { hours }\end{array}$} & $6.1-6.9$ & IFG \\
\hline & $\geq 7.0$ & Diabetes \\
\hline \multirow{2}{*}{$2 \mathrm{hPG}$ in a $75-\mathrm{g} 0 \mathrm{GTT}(\mathrm{mmol} / \mathrm{L})$} & $7.8-11.0$ & IGT \\
\hline & $>11.0$ & Diabetes \\
\hline $\begin{array}{l}\text { Random PG }(\mathrm{mmol} / \mathrm{L}) \\
\text { - Any time of the day without regard to the interval since } \\
\text { the last meal }\end{array}$ & $>11.0$ & Diabetes \\
\hline \multirow{2}{*}{$\begin{array}{l}\text { A1C }(\%) \\
\text { - Standardized, validated assay } \\
\text { - In the absence of factors that affect the accuracy of A1C } \\
\text { - Not for suspected type } 1 \text { diabetes }\end{array}$} & $6.0-6.4$ & Pre-diabetes \\
\hline & $\geq 6.5$ & Diabetes \\
\hline
\end{tabular}

Table 1. Diagnosis of Diabetes 


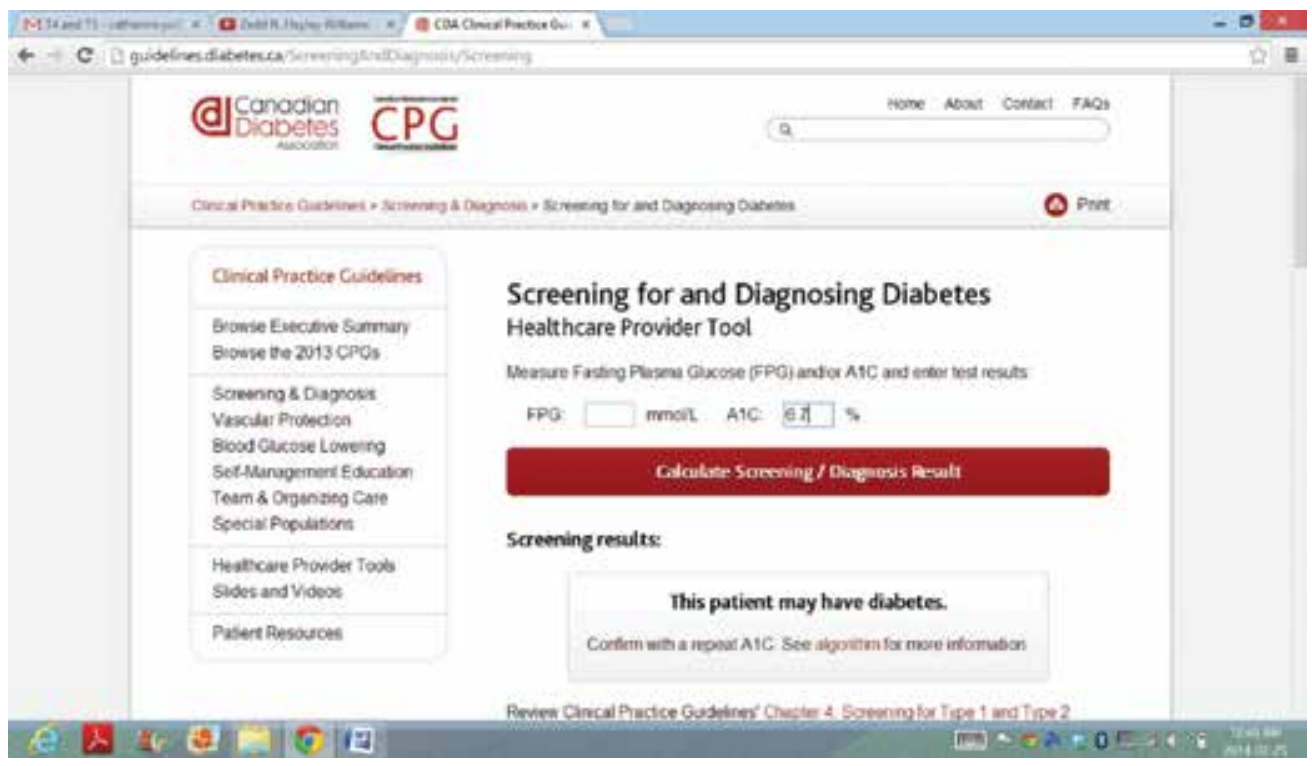

Figure 1.

glycemic control. ${ }^{8}$ The Action to Control Cardiovascular Risk in Diabetes (ACCORD) study also confirmed this finding of reduced microvascular complications with tighter glycemic control, especially with respect to retinopathy. ${ }^{9}$

\section{How Will I Remember This?}

The CDA website and mobile application has a helpful interactive application that allows health care providers to create a target A1C based on each individual's history and key characteristics. $^{3}$

\section{What Is the Next Agent After Metformin in Type 2 Diabetes?}

There are many exciting treatment options for managing type 2 diabetes. The CPG encourages individualization of treatment, based on specific clinical factors, such as presence of renal dysfunction or heart failure and baseline A1C.

New to these guidelines, it is recommended that a baseline A1C of $\leq 8.5 \%$ should be immediately treated with metformin (assuming no contraindications), without an initial 2-3 month period of lifestyle-only management. If an individual presents with symptoms of hyperglycemia and signs of metabolic decompensation, insulin should be the initial management strategy.

\section{How Do I Decide Which Agent to Start?}

The CDA has an interactive tool that provides guidance regarding selection of a second-line treatment option, based on the patient's comorbidities, degree of hyperglycemia, risk of hypoglycemia, agent's cost, and impact on weight. ${ }^{3}$

\section{What's New in Vascular Protection?}

Diabetes and its complications significantly impact the individual, their family, and the health care system. Vascular complications can cause severe morbidity and are the leading cause of death in people with diabetes. ${ }^{9}$

The most recent CPGs continue to recommend a comprehensive and multifaceted approach to reduce cardiovascular risk, including lifestyle interventions, optimal glycemic control, and blood pressure management, with a target of $<130 / 80$. In addition, vascular protection medications, including statins, angiotensin converting enzyme inhibitors (ACEIs), angiotensin receptor blockers (ARBs), and aspirin are recommended, depending on the overall cardiovascular risk of the individual.

\section{If My Patient Has a Low-Density Lipoprotein (LDL) of < $2.00 \mathrm{mmol} / \mathrm{L}$, Does This Mean They Don't Require Statin Therapy?}

No, this is not true. Statin therapy should be used to reduce CV risk in adults with diabetes and macrovascular disease. Based on the Cholesterol Treatment Trialists' (CTT) collaboration meta-analysis, for every $1 \mathrm{mmol} / \mathrm{L}$ reduction in LDLcholesterol (LDL-C), an associated $20 \%$ risk reduction in CV events can be seen, regardless of the baseline LDL. ${ }^{11}$ If statin therapy is initiated, the goal LDL-C is $\leq 2 \mathrm{mmol} / \mathrm{L}$, or if this target is already met, a $50 \%$ or greater reduction. Statin therapy is recommended to all individuals aged 40 years and over who have type 2 diabetes. The evidence is less compelling in type 1 diabetes, though therapy should be considered. 


\section{Should I Use a Statin In a Patient Aged Under $\mathbf{4 0}$ years?} The use of statins in individuals under 40 without macrovascular disease is an area of controversy. The 2013 CPGs suggest statin therapy can be considered in this group if they meet one of the following criteria: 1) they have had diabetes for more than 15 years and are aged over 30 years, 2) they have microvascular complications, or 3) therapy is based on the presence of other risk factors, according to the 2012 Canadian Cardiovascular Society Guidelines. These recommendations stem from knowing the presence of CVD is higher in people with diabetes of longer duration, presence of retinopathy, higher albumin excretion rates, and other traditional Framingham risk factors, such as elevated LDL-C.

\section{When Should I Start an ACE Inhibitor or ARB?}

Based on data from the Heart Outcomes Prevention Evaluation (HOPE) and Ongoing Telmisartan Alone, and in Combination with Ramipril Global Endpoint Trial (ONTARGET) trials, angiotensin-converting-enzyme (ACE) inhibitors or angiotensin receptor blockers (ARBs) are recommended to all patients with diabetes and macrovascular disease and to those aged 50 years and over with at least one traditional CV risk factor or end organ damage (including microalbuminuria). ${ }^{12,13}$ ACEI/ARBs can be considered in all individuals aged 55 years and over, as well as in those aged under 55 years with microvascular disease; however, the evidence is scant in these populations. Whether the CV benefits from ACI inhibitors are independent from their blood pressure lowering effect continues to be hotly debated.

\section{Should I Prescribe Aspirin (ASA) to All of My Patients With Diabetes?}

No, ASA should not be used for primary prevention in diabetes. Meta-analyses looking at diabetes cohorts have shown an overall lack of benefit of ASA in reducing coronary artery disease events and stroke for primary prevention, with an important $50-70 \%$ relative increase in gastrointestinal bleeding. ${ }^{14}$

ASA use may be considered for secondary prevention in people with established CV disease. If aspirin is not tolerated, an alternate anti-platelet (such as clopidogrel or ticagrelor) can be initiated instead.

\section{How Will I Remember This?}

The CDA website has an interactive "vascular protection" application that allows health care professionals to individualize vascular protection medications based on patient age, comorbidities, and duration of diabetes (Figure 3 ). ${ }^{3}$

\section{How to Organize Diabetes Care in Clinical Practice}

To successfully implement these recommendations into clinical care, care must be effectively organized around the person living with diabetes. Adoption of the chronic care model has been demonstrated to improve quality of care and disease outcomes. The chronic care model consists of delivery systems design, self-management support, decision support, clinical information, and linkage with the community and health system.

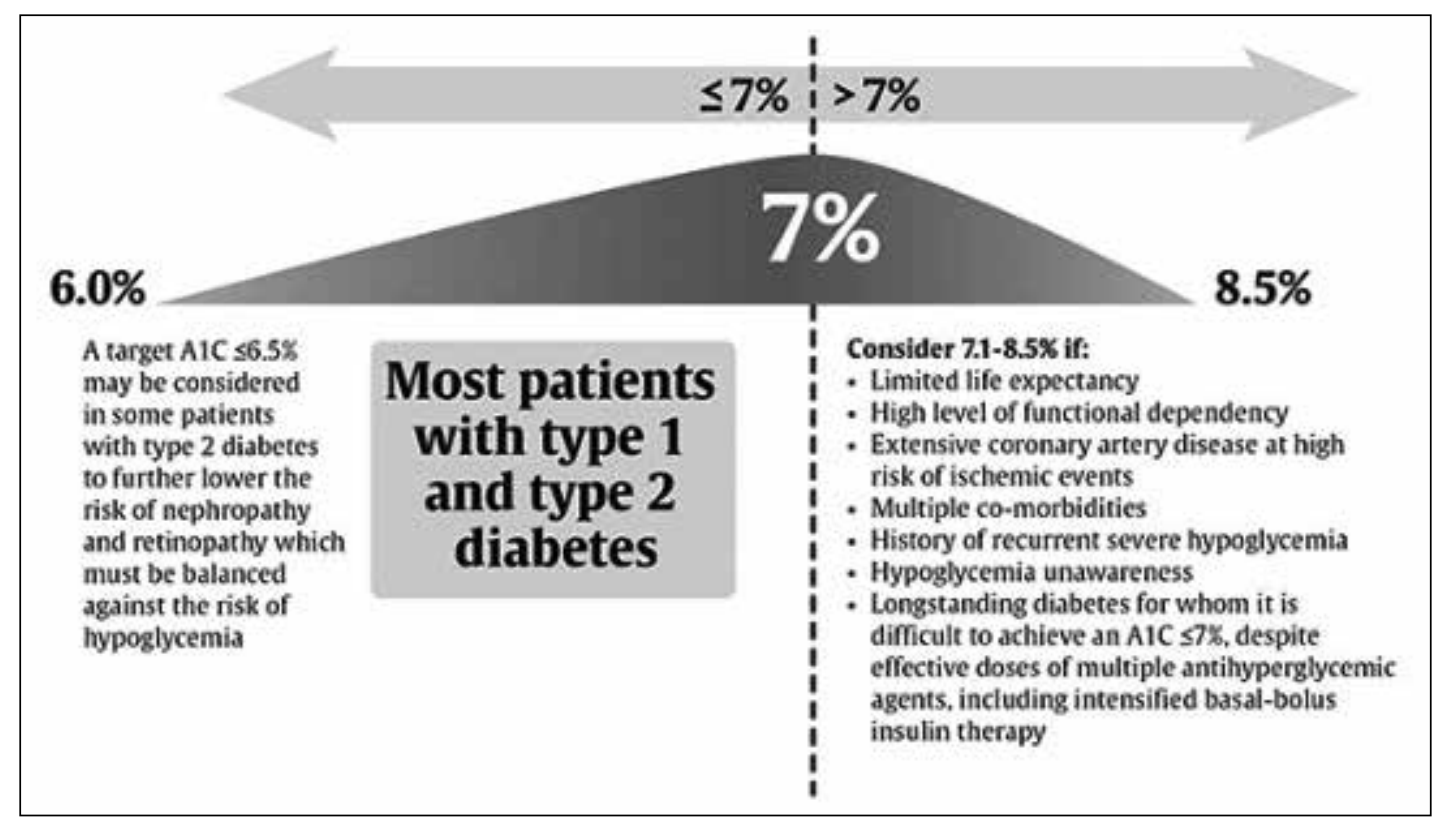

Figure 2. 


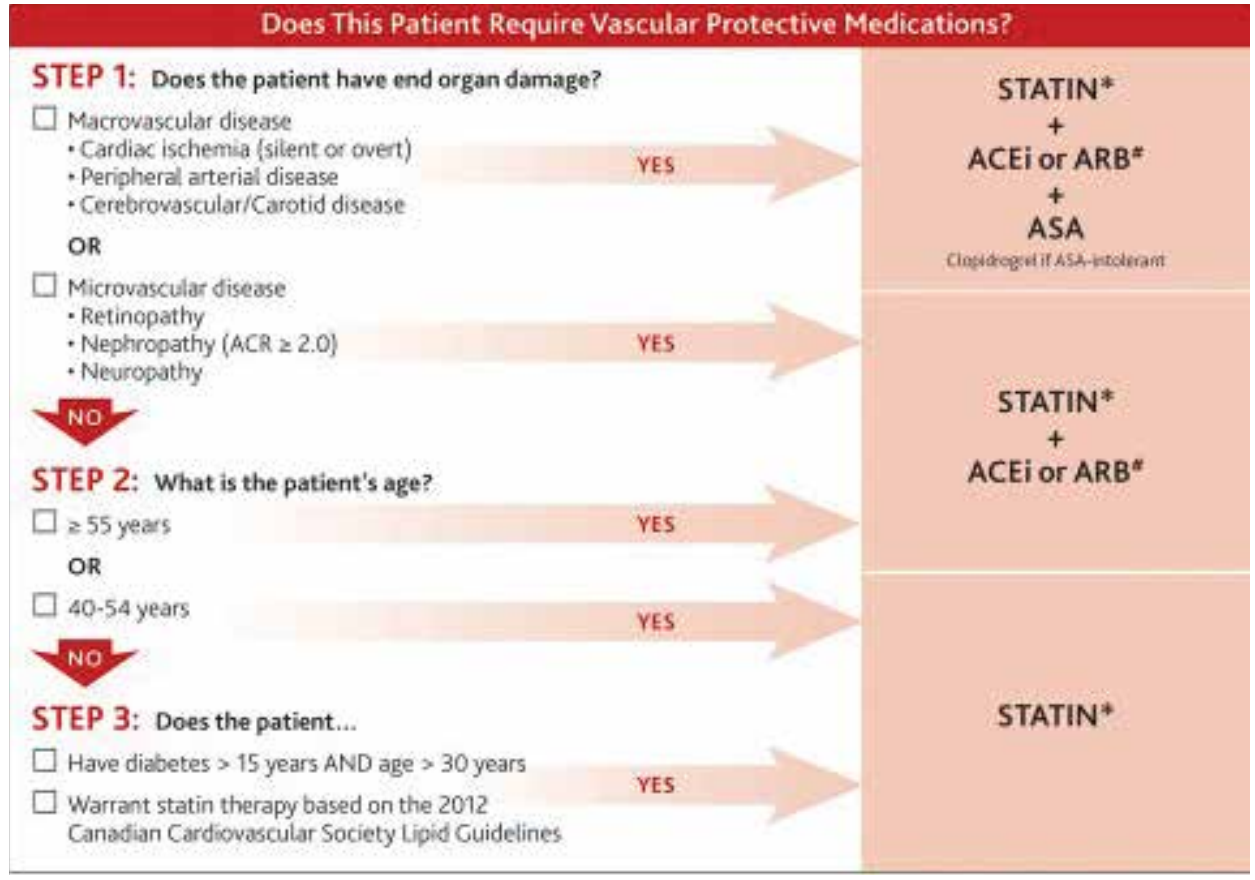

Figure 3.

It can be operationalized through various quality improvement (QI) strategies; this can be summarized with the "five Rs" as follows: 1) recognizing diabetes risk factors with appropriate screening, 2) developing a registry of patients with diabetes, 3) having the appropriate resources available (inter-professional team), 4) relaying information, and 5) creating the opportunity for regular reassessment. Checklists on how to implement these QI strategies can be accessed on the CDA website. ${ }^{3}$

\section{Final Words}

Over the last century, advances in research have transformed diabetes from a condition that inevitably led to death to a chronic condition that can have exceptional outcomes with optimal management. The 2013 CDA guidelines, online interactive tools, and mobile applications allow physicians to deliver the highest quality of diabetes care, by making it easy to put the evidence into practice.

\section{References}

1. Public Health Agency of Canada. Diabetes in Canada: Facts and Figures from a Public Health Perspective. Ottawa; 2011.

2. Canadian Diabetes Association Clinical Practice Guidelines Expert Committee. Canadian Diabetes Association 2013 Clinical Practice Guidelines for the Prevention and Management of Diabetes in Canada. Can J Diabetes 2013;37(Suppl 1):S1-S212.

3. Canadian Diabetes Association Clinical Practice Guidelines Expert Committee. Canadian Diabetes Association 2013 Clinical Practice Guidelines for the Prevention and Management of Diabetes in Canada. Available at: http://guidelines.diabetes.ca/healthcareprovidertools. Accessed April 15, 2015.

4. Stratton IM, Adler AI, Neil HAW, et al. Association of glycaemia with macrovascular and microvascular complications of type 2 diabetes (UKPDS 35): prospective observational study. BMJ 2000;321:405-12.

5. The Diabetes Control and Complications Trial Research Group. The relationship of glycemic exposure (HbA1C) to the risk of development and progression of retinopathy in the Diabetes Control and Complications Trial. Diabetes 1995;44:968-83.

6. Holman RR, Paul SK, Bethel MA, et al. Ten-year follow-up of intensive glucose control in type 2 diabetes. N Engl J Med 2008;359:1577-89.

7. Nathan DM, Cleary PA, Backlund JY, et al. Intensive diabetes treatment and cardiovascular disease in patients with type 1 diabetes. $\mathrm{N}$ Engl J Med 2005;353:2643-53.

8. The ADVANCE Collaborative Group. Intensive blood glucose control and vascular outcomes in patients with type 2 diabetes. $\mathrm{N}$ Engl J Med 2008;358:2560-72.

9. The Action to Control Cardiovascular Risk in Diabetes Study Group. Effects of intensive glucose lowering in type 2 diabetes. N Engl J Med 2008;358:2545-59.

10. Morrish NJ, Wang SL, Stevens LK, et al. Mortality and causes of death in the WHO Multinational Study of Vascular Disease in Diabetes. Diabetologica 2001;44(Suppl 2):S14-S21.

11. Baigent C, Keech A, Kearney PM, et al. Cholesterol Treatment Trialists' (CTT) Collaborators. Efficacy and safety of cholesterol-lowering treatment: prospective meta-analysis of data from 90,056 participants in 14 randomised trials of statins. Lancet 2010;366:1267-78.

12. The Heart Outcomes Prevention Evaluation Study Investigators. Effects of an angiotensin-converting enzyme inhibitor, ramipril, on death from cardiovascular causes, myocardial infarction and stroke in high-risk patients. New Engl J Med 2000;342:145-53.

13. Yusef S, Teo K, Pogue J, et al. Telmisartan, ramipril, or both in patients at high risk for vascular events. N Engl J Med 2008;358:1547-59.

14. Derry S, Loke YK. Risk of gastrointestinal hemorrhage with long-term use of aspirin: meta-analysis. BMJ 2000;321:1183-7. 